\title{
Photocarcinogenesis and Skin Cancer Prevention Strategies: An Update
}

\author{
MARIE CHRISTINE MARTENS, CHRISTINA SEEBODE, JANIN LEHMANN and STEFFEN EMMERT
}

\author{
Clinic and Polyclinic for Dermatology and Venerology, University Medical Center Rostock, Rostock, Germany
}

\begin{abstract}
UV radiation is acknowledged as the primary cause of photocarcinogenesis and therefore contributes to the development of skin cancer entities such as squamous cell carcinoma (SCC), basal cell carcinoma (BCC), and melanoma. Typical DNA photoproducts and indirect DNA damage caused by reactive oxygen species are the result of $U V$ radiation. $U V$ induced DNA damage is repaired by nucleotide excision repair, which consequently counteracts the development of mutations and skin carcinogenesis. Tumour-suppressor genes are inactivated by mutation and growth-promoting pathways are activated leading to disruption of cell-cycle progression. Depending on the skin cancer entity, some genes are more frequently affected than others. In BCC mutations in Patched or Smoothened are common and affect the Sonic hedgehog pathway. In SCC, cell regulator protein $p 53$ (TP53) mutations are prevalent, as well as mutations of the epidermal growth factor receptor (EGFR), cyclin-dependent kinase $2 A$ (CDKN2A), Rat sarcoma (RAS), or the tyrosine kinase Fyn (FYN). UV-induced mutations in TP53 and CDKN2A are frequent in melanoma. $U V$-induced inflammatory processes also facilitate photocarcinogenesis. Recent studies showed a connection between photocarcinogenesis and citrus consumption, phytochemicals, alcohol consumption, hormone replacement therapy, as well as oral contraceptive use. Preventative measures include adequate use of sun protection and skin cancer screening at regular intervals, as well as the use of chemopreventative agents.
\end{abstract}

The prevalent keratinocyte-derived neoplasms of the skin are basal cell and squamous cell carcinomas. Cutaneous

Correspondence to: Professor Dr. med. Steffen Emmert, Clinic for Dermatology and Venereology, University Medical Center Rostock, Strempelstrasse 13, 18057 Rostock, Germany. Tel: +49 3814949701, Fax: +49 3814949702, e-mail: steffen.emmert@med.uni-rostock.de

Key Words: Photocarcinogenesis, UV light, skin tumors, DNA repair, prevention strategies, review. melanoma is less frequent, but associated with high mortality. Photocarcinogenesis follows a multistep model of cancer development in which ultraviolet (UV)-induced DNA damage leads to mutations resulting in activation of oncogenes or silencing of tumor-suppressor genes. This ends in a cellular mutator phenotype even more prone to the acquisition of mutations. DNA repair, especially the nucleotide excision repair (NER) pathway, counteracts mutation formation and skin cancer development. Primary skin cancer preventative strategies therefore include reduction of photodamage to DNA.

\section{The Electromagnetic Spectrum of Sunlight}

Photocarcinogenesis is defined as a multistep progression of skin cancer caused by electromagnetic waves of the optical spectrum. This includes the activation of oncogenes and suppression of tumour suppressors and depends on the applied dosage, the duration of exposure, and the wavelength of the irradiation. The optical spectrum consists of UV radiation (100-400 $\mathrm{nm}$ ), visible light (400-760 $\mathrm{nm}$ ), and infrared radiation (IR; $760 \mathrm{~nm}-1 \mathrm{~mm}$ ) belonging to the non-ionizing part of the electromagnetic spectrum. UV radiation is further subdivided into three wavelength ranges: UVC radiation $(100-280 \mathrm{~nm})$ has the shortest wavelength and is also the most energetic. Its high mutagenic potential does not reach the earth's surface due to the formation of ozone from oxygen in the stratosphere which blocks it. UV-B radiation (280-315 $\mathrm{nm}$ ) and UV-A radiation $(315-400 \mathrm{~nm})$ are able to penetrate the atmosphere and therefore cause direct and indirect DNA damage, resulting in mutations, inflammation, sunburn, immunosuppression, and as a long-term consequence, skin cancer. While UV-B radiation is mostly absorbed by the epidermis, UV-A radiation penetrates into the deep dermal layers of the skin. UV-A radiation (90-95\%) presents the largest fraction of UV radiation reaching the earth's surface compared to UV-B radiation (5-10\%). IR radiation is also subdivided into three wavelength ranges: IR-A (760-1440 
$\mathrm{nm})$, IRB (1440-3000 nm), and IRC (3,000 nm-1 mm). Only IR-A is able to penetrate all three layers of the skin. Comparing the amount of different wavelengths of solar radiation reaching the skin, IR-A radiation represents $54 \%$, while UV radiation only amounts to $7 \%$ (1-4). Although IR radiation is known to be imbed in photo aging and photocarcinogenesis (4), research labels UV radiation as the primary cause of photocarcinogenesis and therefore nonmelanoma skin cancer (NMSC) such as squamous cell carcinoma (SCC) and basal cell carcinoma (BCC), as well as melanoma (1). Additionally, the effect of IR-A protection in sunscreens is highly contradictory $(5,6)$. Hence, we subsequently focus on UV-dependent carcinogenesis.

\section{UV-Specific Impact on DNA}

DNA is a chromophore for UV radiation, having an absorption maximum at $254 \mathrm{~nm}$. UV-B radiation is directly absorbed by DNA and generates DNA photoproducts such as cyclobutane pyrimidine dimers (CPDs) and 6-pyrimidine-4pyrimidone dimers (6-4 PPs). At a ratio of 2:1, CPDs are more frequent than 6-4 PPs. These photoproducts lead to bulky lesions in DNA that distort the DNA backbone due to mismatches of bases or photoproducts and therefore block polymerases for transcription and replication $(2,7)$. Only nucleotide excision repair (NER) removes these errors from the DNA. Defects in NER lead to the rare autosomalrecessive disease xeroderma pigmentosum [a comprehensive review can be found in (8)].

UV-A and UV-B radiation also lead to the formation of reactive oxygen species (ROS) that attack DNA, proteins and cell membranes through oxidation. They can also cause single strand DNA breaks (9).

\section{Clinical Picture of UV-Associated Damage}

The clinical picture is dominated by sunburn (dermatitis solaris) caused by acute UV-B radiation. The typical erythema is accompanied by oedematous swelling and sometimes blistering, followed by desquamation and pigmentation of the affected skin. Histologically, 12-72 hours after UV-B exposure, apoptotic cells can be found in the stratum granulosum (10). As a natural protective mechanism against UV radiation, melanocytes produce the dark pigment melanin. A melanin cap above the nucleus absorbs UV radiation and partially visible light as well as IR radiation. In addition, it functions as a radical scavenger (11). UVA/UV-B-mediated immediate pigment darkening can probably be accounted for by photo-oxidation of melanin precursors and is rapidly reversible. Long-term late pigment darkening sets in 2 to 3 days after exposure. The pigment production in melanocytes of the basal layer of the epidermis is stimulated, providing melanin for keratinocytes. While
UV-A exposure leads to immediate pigment darkening, both UV-A and UV-B exposure are responsible for late pigment darkening. Additionally, chronic UV radiation triggers acanthosis and hyperkeratosis. Radiation has to penetrate deeper to reach the basal layer in order to inflict serious damage. Therefore, actinic acanthosis and skin darkening represent natural protective mechanism of the skin against UV-induced skin damage (12-14).

\section{Cutaneous Cancers and Their Genomic Background}

The most common cancers of the skin are SCCs and BCCs. Both entities originate from the same cell type keratinocytes. However, depending on the cancer type, some genes are more affected than others that drive the entity formation. While Patched (PTCH) and Smoothened (SMO) mutations that influence the Sonic hedgehog (SHH) pathway are prevalent in BCC, driver genes in SCC include those of the cell regulator gene p53 (TP53) producing defective TP53 protein, mutations of the epidermal growth factor receptor $(E G F R)$, Rat sarcoma $(R A S)$, tyrosine kinase Fyn $(F Y N)$, and cyclin-dependent kinase 2A (CDKN2A) (2, $15)$. Both types of NMSC are mostly found in the older population, although the incidence in the young population is increasing $(15,16)$. A precursor stage of SCC is actinic keratosis (AK) that represents an in situ transformation. However, only a minor proportion of cases of AK actually progress into invasive SCC, and in many cases these skin lesions regress spontaneously. Melanoma exhibits different UV-induced driver mutations including those of TP53 and CDKN2A (17). Generally, tumour-suppressor genes are inactivated and growth-promoting pathways are activated, disturbing the normal growth behaviour of keratinocytes and melanocytes $(11,15)$.

\section{Molecular Mechanisms of Photocarcinogenesis}

Mutations. Different molecular mechanisms underlie the formation of skin cancer. The proliferation-promoting effect of UV-B radiation is, amongst others, mediated by the mitogen-activated protein kinase (MAPK) pathway. The guanosine phosphate-binding RAS protein is located on the inner cell membrane and represents one of three oncogene family members that are involved in this pathway. Activating RAS mutations lead to a continuous growth signal that no longer depends on receptors. Therefore, it causes tumour development. RAS mutations have been shown to be present in a multitude of epithelial tumours on sun-exposed skin. The reason for its susceptibility to mutations is considered to be the amount of pyrimidine-containing sequences. Both point mutations and gene amplification of RAS are involved in skin cancer development (1). 
SHH signalling holds a leading role during embryogenesis. BCCs often exhibit abnormal activation of the SHH pathway causing this neoplasia. This abnormal activation is caused by mutations in PTCH (30-40\% of all sporadic BCCs), and mutations in SMO (approximately $20 \%$ of all sporadic BCCs). Mutations uncoupling SMO and PTCH1 from SHH signalling prompt cell proliferation and tumour growth $(15,18)$.

In its physiological function, TP53 promotes cell-cycle arrest in G1 phase using cyclin-dependent kinases (CDK) to enable DNA repair before the start of $S$ phase. After recognizing DNA damage, a kinase cascade is set in motion [serine-threonine protein kinase] phosphorylates checkpoint kinase 1 /checkpoint kinase $2(\mathrm{CHK} 1 / \mathrm{CHK} 2)]$ that finally leads to the phosphorylation and, consequently, activation of the cell regulator protein $\mathrm{p} 53 \mathrm{~T}$ (TP53) by the detachment of murine double minute oncogene (MDM2), which is an associated ubiquitin ligase. Phosphorylated p53 induces $p 21$ which in turn halts the cell cycle in G1 phase by binding to and inhibiting CDK-cyclin complexes. Additionally, p53 can induce apoptosis through activation of the intrinsic pathway, which leads to the release of cytochrome $c$ from the mitochondria (19-21). By interacting with xeroderma pigmentosum-associated proteins, it facilitates NER and thus suppresses tumour development. BCCs and SCCs exhibit specific mutations in TP53 that differ from mutations in neighbouring non-cancerous cells. Mutations in TP53 can initiate skin cancer development (1).

$C D K N 2 A$ encodes two powerful tumour suppressors that are involved in cell-cycle regulation. $\mathrm{p} 16^{\mathrm{INK} 4 \mathrm{~A}}$ prevents cellcycle progression from $\mathrm{G}_{1}$ to $\mathrm{S}$ phase by binding to CDK4/CDK6 and thereby inhibiting phosphorylation of the retinoblastoma protein. $\mathrm{p} 14^{\mathrm{ARF}}$ stabilizes the level of TP53 and therefore prevents oncogenic transformation $(15,22)$. UV signature mutations were identified in CDKN2A (23).

In 2016, a study identified dysregulated UV target genes in human skin cancer through transcriptome analysis. They first identified conserved UV signature genes and then performed similar tests comparing the transcriptome of human SCC tissue and adjacent normal skin. While significant numbers of down-regulated genes accumulated in top biological pathways, including cell-cycle regulation, chromosomal structure, DNAdamage response and microtubule organization, up-regulated genes accumulated in pathways including apoptosis, defence inflammatory response, ectoderm epithelial development, cell adhesion, and leukocyte activation. A significant proportion of the UV signature genes were shown to be dysregulated in human skin SCCs. The same could not be shown for other human malignancies. Therefore, UV signature genes show potential for clinical diagnosis of UV damage and stratification of skin cancer risk (24).

Photocarcinogenesis-promoting processes. Nuclear factor kappa-light-chain-enhancer of activated $\mathrm{B}$-cells $(\mathrm{NFKB})$ is a transcription factor that is involved in inflammation, cell cycle regulation, and cell survival. In its inactive form, NFKB is bound to inhibitor of kappa B ( IкB) in the cytoplasm. By stimuli-dependent phosphorylation of IkB by IkB kinases, NFkB dissociates from IkB. UV radiation is one of such stimuli. NFKB is translocated into the nucleus where it stimulates the transcription of effector genes (25).

Signal transducer and activator of transcription 3 (STAT3) is activated by UV radiation in human keratinocytes and fibroblasts through DNA damage and ROS formation. STAT3 is constitutively active in various human cancer entities and has been shown to be required for cell proliferation and tumorigenesis in SCC cell lines. It also inhibits apoptosis (26-28).

Additionally, inflammation of the skin is promoted by cyclooxygenases (COX), particularly $C O X 2$. COX2 is a rapidly inducible gene, which can be induced by UV radiation. COX2 synthesizes prostaglandins from arachidonic acid. Hence, it maintains the inflammatory process. Due to UV radiation increasing the amount of arachidonic acid, UV exposure leads to an increased prostaglandin synthesis in the skin. Elevated prostaglandin levels have been shown to be present in BCCs and SCCs, contributing to carcinogenesis and tumour progression (29-31).

Tryptophan is a chromophore for UV-B radiation. UV-B radiation leads to the production of 6-formylindolo[3,2b]carbazole from tryptophan, which in turn is a ligand of the aryl hydrocarbon receptor (AHR). The AHR is a ligandactivated transcription factor and is an important regulator of drug metabolism. It has been shown that the AHR not only induces COX2 in human keratinocytes but also displays an anti-apoptotic effect due to its influence on checkpoint kinase $1(C H K 1)$ and E2F transcription factor 1 (E2F1). Inhibition of the AHR dampened the anti-apoptotic effect and also reduced the induction of $\operatorname{COX} 2(32,33)$.

\section{Further Influences on Photocarcinogenesis}

The function of vitamin D, a hormone that is mainly produced from precursors in human skin under the influence of UV-B radiation, has long been known to be important in the control of calcium and bone metabolism. Recently, it was discovered that the skin is also a target tissue for vitamin D. The VDR was found to act in conjunction with TP53 and other factors as a tumor suppressor in response to alterations of cell homeostasis such as UV-induced DNA damage. Through VDR binding, vitamin D is able to indirectly regulate the cell cycle and other proteins involved in cell proliferation and differentiation. Other pathways such as $\mathrm{SHH}$ signalling that are pivotal for cell growth are also controlled by vitamin D. Vitamin D is also involved in immunological reaction in the skin leading to both immunosuppression and stimulation of distinct immunoregulatory pathways (34). 
Lycopene is a potent antioxidant. It has been shown to exhibit strong antiproliferative properties by modulating the cell cycle and apoptosis. A recent study discovered that pretreatment with lycopene attenuated UV-B-induced cell hyperproliferation and promoted apoptosis in human keratinocytes and SKH-1 hairless mice. Forkhead box O3a (FOXO3a) is important for cell death-related gene expression. It is phosphorylated in response to UV-Bradiation and is sequestered in the cytoplasm. A connection between loss of FOXO3a and reduced lycopene-induced effects point to a significant role for FOXO3a in the regulation of the effects of lycopene (35).

\section{Recent Studies Investigating Dietary Influence on Photocarcinogenesis}

A higher skin cancer risk was attributed to furocoumarins, a group of chemicals that naturally occur in citrus products. Furocoumarins exhibit high UV-A absorption and are strongly mutagenic. In their excited state, they react with biomolecules, especially with pyrimidine bases of DNA. The furocoumarin derivate psoralen is often used together with UV-A radiation in psoriasis treatment; this could explain the elevated BCC and SCC risk of patients treated in this way $(36,37)$.

The dietary influence of pomegranate is attributed to its high anti-oxidative activity, its ability to influence multiple cell signalling pathways, as well as its anti-inflammatory and antiproliferative properties. Pomegranate seed oil, pomegranate fruit extract, and pomegranate juice have been tested in cell culture and reconstituted human skin models and animal models of skin cancer and were found to exhibit a high potential for prevention of UV-B-induced skin cancer (38).

Piperine is a plant alkaloid that is present in black pepper. A recent study showed that it acts as a scavenger for free radicals. It also inhibits DNA damage-mediated cell cycle arrest and apoptosis and inhibits UV-induced activation of NFkB. Therefore, the authors suggest its applicability for human use (39).

Another study correlated an elevated risk for BCC with the consumption of alcohol, irrespective of gender. It has been theorized that on the one hand intermediate byproducts or metabolites of alcohol are directly mutagenic or carcinogenic, while on the other hand, they act as photosensitizers and generate ROS. Furthermore, alcoholinduced immunosuppression may increase cancer risk. High alcohol consumption may also just be an indicator of a general unhealthy lifestyle. UV radiation in combination with alcohol was shown to induce skin cancer (40).

A correlation between the use of oral contraceptives or menopausal hormone therapy (MHT) and NMSC risk was assessed in a nationwide cohort study in the US. As the photosensitizing effects of oestrogen are well recognized, the relationship between exogenous oestrogen use, reproductive factors, and first primary BCC was evaluated, taking sun exposure and personal sun sensitivity into account (41). In particular, women using MHT had a higher risk for BCC (42).

\section{Skin Cancer Prevention}

Due to skin cancer incidence dramatically increasing over the last few years, primary prevention has become highly important. In Germany, while in 2003 the number of new melanoma cases was 14,044, in 2013, 20,163 new cases were reported. The number of new NMSC cases in Germany in 2003 was 70,682 and had increased to 134,219 in 2013. Therefore, the number has nearly doubled in that time period (43). As solar UV radiation represents the most important environmental risk factor for the development of skin cancer (44), behavioural protection against UV radiation is a fundamental part of skin cancer prevention. Adequate measures to reduce UV exposure include avoiding direct exposure to midday sun (between 10 am and $2 \mathrm{pm}$ ), protection with appropriate clothing, and the use of sunscreens against both UV-A and UV-B radiation with a minimum sun protection factor of 15-20. Regularly performed self-examinations and annual full-body skin cancer examination performed by a dermatologist - at more frequent intervals for high-risk patients if necessary increase the likelihood of detecting any skin changes that can then be diagnosed at an early and curable stage (45).

Additional strategies for skin cancer prevention are currently being investigated. Particularly high-risk patients who developed NMSC twice within the 5 years showed promising results using $500 \mathrm{mg}$ nicotinamide (vitamin $\mathrm{B}_{3}$ ) twice daily as a chemoprevention. A reduced occurrence of NMSC by $23 \%$ compared to the placebo-treated group was shown in a phase III study (BCC: 20\%, SCC: $30 \%$, actinic keratosis: 13\%). This therapy is based on the fact that UV radiation leads to ATP depletion, hindering DNA repair. Nicotinamide prevents ATP depletion and glycolytic blockade, and DNA repair is thereby enhanced. Immunosuppression due to UV radiation is also reduced. The drug is already used in the clinical treatment of autoimmune blistering disorders, such as bullous pemphigoid (46).

Other chemopreventional strategies include the use of phytochemicals as they show low toxicity and anticarcinogenic properties. Phytochemicals such by those as described in the article by Montes de Oca et al. are extracted from plants and are used topically or orally to prevent or protect against skin cancer (47). Hydrophilic hydroxyl groups, often as part of a polyphenol group, act as antioxidants by scavenging ROS or free radicals. Therefore, oxidative damage to DNA, proteins and lipids is inhibited. They also have anti-inflammatory properties and have been shown to modulate the cell cycle, cell proliferation and angiogenesis (48). 
A smartphone application, called mISkin, was designed to promote sun protection during holidays taking previously tested interventions into consideration. The application reminds the user to use appropriate sun protection based on their location and provides information about how to apply sunscreen and using other methods of sun protection, elaborating on the risk of unprotected sun exposure. It also includes a Sun Safety Quiz and a Sun Alert Service that alerts the user to use sun protection at a customized rate (49).

In summary, sunlight-induced DNA damage and the resulting mutations in several driver genes for cancer development contribute to a substantial proportion of multistep cancer development. Induction of such mutations can be targeted by personal behaviour and therefore be avoided. In addition, new chemopreventional strategies such as the intake of nicotinamide (vitamin $\mathrm{B}_{3}$ ) are emerging that enhance DNA repair at the cellular lever and also lead to a reduction in the mutational load of cells.

\section{Acknowledgements}

The Authors would like to thank the German Cancer Aid (Deutsche Krebshilfe e.V.) [111377], the Damp Foundation, and the Deutsche Stiftung Dermatologie for funding. We based this review on our previous publication elaborating on new developments in the field of photocarcinogenesis (2).

\section{References}

1 Melnikova VO and Ananthaswamy HN: Cellular and molecular events leading to the development of skin cancer. Mutat Res 571: 91-106, 2005.

2 Seebode C, Lehmann J and Emmert S: Photocarcinogenesis and skin cancer prevention strategies. Anticancer Res 36: 1371-1378, 2016.

3 Black HS, deGruijl FR, Forbes PD, Cleaver JE, Ananthaswamy HN, deFabo EC and Ullrich SE TR: Photocarcinogenesis: an overview. J Photochem Photobiol B 40: 29-47, 1997.

4 Holzer AM, Athar M and Elmets CA: The other end of the rainbow: infrared and skin. J Invest Dermatol 130: 1496-1499, 2010.

5 Zastrow L and Lademann J: Light - Instead of UV protection: new requirements for skin cancer prevention. Anticancer Res 36: 1389-1393, 2016

6 Diffey B and Cadars B: An appraisal of the need for infrared radiation protection in sunscreens. Photochem Photobiol Sci 15: 361-364, 2016.

7 Vink AA and Roza L: Biological consequences of cyclobutane pyrimidine dimers. J Photochem Photobiol B 65: 101-104, 2001.

8 Lehmann J, Schubert S and Emmert S: Xeroderma pigmentosum: diagnostic procedures, interdisciplinary patient care, and novel therapeutic approaches. J Dtsch Dermatol Ges 12: 867-872, 2014.

9 Ichihashi M, Ueda M, Budiyanto A, Bito T, Oka M, Fukunaga $\mathrm{M}$, Tsuru $\mathrm{K}$ and Horikawa $\mathrm{T}$ : UV-induced skin damage. Toxicology 189: 21-39, 2003.

10 Berking C: Photokarzinogenese. Der Hautarzt 58: 398-405, 2007.
11 Hussein M: Ultraviolet radiation and skin cancer: molecular mechanisms. J Cutan Pathol 32: 191-205, 2005.

12 Young AR: Acute effects of UVR on human eyes and skin. Prog Biophys Mol Biol 92: 80-85, 2006.

13 Kadekaro AL, Kavanagh RJ, Wakamatsu K, Ito S, Pipitone MA and Abdel-Malek ZA: Cutaneous photobiology. The melanocyte vs. the sun: Who will win the final round? Pigment Cell Res 16: 434-447, 2003.

14 Irwin C, Barnes A, Veres D and Kaidbey K: An ultraviolet radiation action spectrum for immediate pigment darkening. Photochem Photobiol 57: 504-507, 1993.

15 Emmert S, Schön MP and Haenssle HA: Molecular biology of basal and squamous cell carcinomas. Adv Exp Med Biol 810: 234-252, 2014

16 Christenson LJ, Borrowman TA, Vachon CM, Tollefson MM, Otley CC, Weaver AL and Roenigk RK: Incidence of basal cell and squamous cell carcinomas in a population younger than 40 years. JAMA 294: 681-690, 2005.

17 Hodis E, Watson IR, Kryukov GV, Arold ST, Imielinski M, Theurillat JP, Nickerson E, Auclair D, Li L, Place C, Dicara D, Ramos AH, Lawrence MS, Cibulskis K, Sivachenko A, Voet D, Saksena G, Stransky N, Onofrio RC, Winckler W, Ardlie K, Wagle N, Wargo J, Chong K, Morton DL, Stemke-Hale K, Chen G, Noble M, Meyerson M, Ladbury JE, Davies MA, Gershenwald JE, Wagner SN, Hoon DSB, Schadendorf D, Lander ES, Gabriel SB, Getz G, Garraway LA and Chin L: A landscape of driver mutations in melanoma. Cell 150: 251-263, 2012.

18 Athar M, Li C, Kim AL, Spiegelman VS and Bickers DR: Sonic hedgehog signaling in basal cell nevus syndrome. Cancer Res 74: 4967-4975, 2014.

19 Oren M: Regulation of the p53 tumor-suppressor protein. J Biol Chem 274: 36031-36034, 1999.

20 Khanna KK and Jackson SP: DNA double-strand breaks: signaling, repair and the cancer connection. Nat Genet 27: 247254, 2001.

21 Fridman JS and Lowe SW: Control of apoptosis by p53. Oncogene 22: 9030-9040, 2003.

22 Sharpless NE and Chin L: The INK4a/ARF locus and melanoma. Oncogene 22: 3092-3098, 2003.

23 Saridaki Z, Liloglou T, Zafiropoulos A, Koumantaki E, Zoras O and Spandidos D: Cutaneous biology mutational analysis of CDKN2A genes in patients with squamous cell carcinoma of the skin. Br J Dermatol 148: 638-648, 2003.

24 Shen Y, Kim AL, Du R and Liu L: Transcriptome analysis identifies the dysregulation of ultraviolet target genes in human skin cancers. PLoS One 11: e0163054, 2016.

25 Muthusamy V and Piva TJ: The UV response of the skin: A review of the MAPK, NFKB and TNF $\alpha$ signal transduction pathways. Arch Dermatol Res 302: 5-17, 2010.

26 Bito T, Sumita N, Masaki T, Shirakawa T, Ueda M, Yoshiki R, Tokura $\mathrm{Y}$ and Nishigori C: Ultraviolet light induces Stat3 activation in human keratinocytes and fibroblasts through reactive oxygen species and DNA damage. Exp Dermatol 19: 654-660, 2010.

27 Sumita N, Bito T, Nakajima K and Nishigori C: Stat3 activation is required for cell proliferation and tumorigenesis but not for cell viability in cutaneous squamous cell carcinoma cell lines. Exp Dermatol 15: 291-299, 2006.

$28 \mathrm{Wu} \mathrm{J}, \mathrm{Lu} \mathrm{W}$ and Cui L: Clinical significance of STAT3 and MAPK phosphorylation, and the protein expression of cyclin D1 
in skin squamous cell carcinoma tissues. Mol Med Rep: 81298134, 2015.

29 Fischer SM, Pavone A, Mikulec C, Langenbach R and Rundhaug JE: Cyclooxygenase-2 expression is critical for chronic UV-induced murine skin carcinogenesis. Mol Carcinog 46: 363-371, 2007.

30 Sivrikoz ON, Uyar B, Dag F, Tasli F and Sanal SM: Cxcr-4 and cox-2 expression in basal cell carcinomas and well-differentiated squamous cell carcinomas of the skin; their relationship with tumor invasiveness and histological subtype. Turkish J Pathol: 30-35, 2014.

31 Buckman SY, Gresham A, Hale P, Hruza G, Anast J, Masferrer $\mathrm{J}$ and Pentland AP: COX2 expression is induced by UV-B exposure in human skin: implications for the development of skin cancer. Carcinogenesis 19: 723-729, 1998.

32 Fritsche E, Schäfer C, Calles C, Bernsmann T, Bernshausen T, Wurm M, Hübenthal U, Cline JE, Hajimiragha H, Schroeder P, Klotz L-O, Rannug A, Fürst P, Hanenberg H, Abel J and Krutmann $\mathrm{J}$ : Lightening up the UV response by identification of the arylhydrocarbon receptor as a cytoplasmatic target for ultraviolet B radiation. Proc Natl Acad Sci USA 104: 8851-8856, 2007.

33 Frauenstein K, Sydlik U, Tigges J, Majora M, Wiek C, Hanenberg H, Abel J, Esser C, Fritsche E, Krutmann J and Haarmann-Stemmann T: Evidence for a novel anti-apoptotic pathway in human keratinocytes involving the aryl hydrocarbon receptor, E2F1, and checkpoint kinase 1. Cell Death Differ 20: 1425-1434, 2013

34 Reichrath J, Saternus R and Vogt T: Endocrine actions of vitamin D in skin: Relevance for photocarcinogenesis of nonmelanoma skin cancer, and beyond. Mol Cell Endocrinol 453: 96-102, 2017.

35 Chen P, Xu S and Qu J: Lycopene Protects Keratinocytes Against UV-B Radiation-Induced Carcinogenesis via negative regulation of FOXO3a through the mTORC2/AKT signaling pathway. J Cell Biochem 9999: 1-12, 2017.

$36 \mathrm{Wu}$ S, Cho E, Feskanich D, Li WQ, Sun Q, Han J and Qureshi AA: Citrus consumption and risk of basal cell carcinoma and squamous cell carcinoma of the skin. Carcinogenesis 36: 1162$1168,2015$.

37 Wu S, Han J, Feskanich D, Cho E, Stampfer MJ, Willett WC and Qureshi AA: Citrus consumption and risk of cutaneous malignant melanoma. J Clin Oncol 33: 2500-2508, 2015.

38 Sharma P, McClees SF and Afaq F: Pomegranate for prevention and treatment of cancer: an update. Molecules 22: 177-178, 2017.

39 Verma A, Kushwaha HN, Srivastava AK, Srivastava S, Jamal N, Srivastava K and Ray RS. Piperine attenuates UV-R induced cell damage in human keratinocytes via NF-kB, BAX/BCL-2 pathway: An application for photoprotection. J Photochem Photobiol B 172: 139-148, 2017.
$40 \mathrm{Wu}$ S, Li W-Q, Qureshi AA and Cho E: Alcohol consumption and risk of cutaneous basal cell carcinoma in women and men. Am J Clin Nutr 102: 1158-1166, 2015.

41 Kuklinski LF, Zens MS, Perry AE, Gossai A, Nelson HH and Karagas MR: Sex hormones and the risk of keratinocyte cancers among women in the United States: A population-based casecontrol study. Int J Cancer 139: 300-309, 2016.

42 Cahoon EK, Kitahara CM, Ntowe E, Bowen EM, Doody MM, Alexander BH, Lee T, Little MP, Linet MS and Freedman DM: Female estrogen-related factors and incidence of basal cell carcinoma in a nationwide us cohort. J Clin Oncol 33: 40584065, 2015.

43 Gesellschaft der epidemiologischen Krebsregister in Deutschland e.V.: Atlas der Krebsinzidenz und Krebsmortalität "Der GEKID Atlas", pp. 3,14 and 15, 2016.

44 Reichrath J and Nürnberg B: Cutaneous vitamin D synthesis versus skin cancer development: The Janus faces of solar UVradiation. Dermatoendocrinol 1: 253-261, 2009.

45 Gritz ER, Tripp MK, De Moor CA, Eicher SA, Mueller NH and Spedale JH: Skin cancer prevention counseling and clinical practices of pediatricians. Pediatr Dermatol 20: 16-24, 2003.

46 Chen AC, Martin AJ, Choy B, Fernández-Peñas P, Dalziell RA, McKenzie CA, Scolyer RA, Dhillon HM, Vardy JL, Kricker A, St. George G, Chinniah N, Halliday GM and Damian DL: A phase 3 randomized trial of nicotinamide for skin-cancer chemoprevention. N Engl J Med 373: 1618-1626, 2015.

47 Montes de Oca MK, Pearlman RL, McClees SF, Strickland R and Afaq F: Phytochemicals for the prevention of photocarcinogenesis. Photochem Photobiol 93: 956-974, 2017.

48 Oliver B, Durrani S, Cohen JL and Friedman AJ: Current Perspectives Among U.S. Dermatologists on chemoprevention of nonmelanoma skin cancer: a survey-based study. J Drugs Dermatology 16: 449-452, 2017.

49 Rodrigues AM, Sniehotta FF, Birch-Machin MA, Olivier P and Araujo-Soares V: Systematic and iterative development of a smartphone app to promote sun-protection among holidaymakers: Design of a prototype and results of usability and acceptability testing. JMIR Res Protoc 6: e112, 2017. 